\title{
How HSS, the Most Trusted Educator in Musculoskeletal Health, Is Addressing the Opioid Crisis
}

\author{
Louis A. Shapiro
}

Received: 27 November 2018/Accepted: 30 November 2018/Published online: 8 January 2019

(C) Hospital for Special Surgery 2019

From the time we woke up this morning to the time we wake up tomorrow, an estimated 130 Americans will die of opioid overdose [5]. Every health care provider has a role in solving this crisis. If you are an emergency room physician, for example, the challenge may be different than if you are an orthopedic surgeon. Orthopedic surgeons work with patients whose conditions involve acute and chronic pain, and orthopedists therefore have one of the highest rates of opioid prescribing in the USA [6]. We therefore need to rely on varying perspectives in addressing the overdose epidemic.

At the Hospital for Special Surgery (HSS), we do a fair number of joint replacements - approximately 200 a day - and we recognize that arthroplasty is a good place to begin a discussion on the role of opioids in managing postoperative pain. That was the challenge of the multidisciplinary group HSS Journal ${ }^{\circledR}$ convened on June 1, 2018, for a meeting called Toward Opioid-Free Arthroplasty: A Leadership Forum.

This invitational forum sought to examine the opioid epidemic and potential solutions from several angles. As President and CEO at HSS for the past 12 years, I have come to understand that many factors have conspired to exacerbate this crisis. Among them are socioeconomic issues [1], the rapid increase of deaths from heroin and fentanyl coupled with lax policy and regulatory oversight [3], the overprescribing of opioids [4], and medical norms developed as unintended consequences of quality-improvement efforts targeted at eliminating pain [2]. Forum participants discussed these and other factors and sought to come to a consensus on appropriate pain management after knee or hip replacement.

Electronic supplementary material The online version of this article (https://doi.org/10.1007/s11420-018-09660-0) contains supplementary material, which is available to authorized users.

L. A. Shapiro, $(\bowtie)$

Hospital for Special Surgery,

535 East 70th Street,

New York, NY 10021, USA

e-mail: shapirol@hss.edu
HSS is always about three things: our clinical, academic, and research work. Our education mission is for HSS to be "the most trusted educator" in musculoskeletal health. We view it as an immense responsibility to share within and outside our enterprise the knowledge we acquire so that everyone can benefit from what we learn. A case in point is the Controlled Substances Task Force at HSS that for several years has had four goals: (1) to prescribe opioids responsibly and promote conservative use; (2) to optimize each patient's surgical experience and tailor treatment plans to individual complex pain needs; (3) to provide education and supporting resources to prescribers, patients, and the community; and (4) to invest in opioid-related research and track outcomes to support better care.

Our task force consists of an impressive and growing team of professionals who are both intelligent and passionate about tackling the opioid crisis. For surgical patients, the process begins with identifying patients' needs as early as possible, when they get to the physician's office. They get screened comprehensively and receive a tailored pain-management regimen that very likely differs from that of other patients. It is also important that clinicians not forget about patients once they leave the care environment, when a new set of challenges arises.

At HSS in 2018, 500,000 fewer short-acting opioid pills will be prescribed-from 2 million to 1.5 million pills - through the work of the task force.

To all who attended our forum, and to those of you reading this special issue that has grown out of it, I thank you for your commitment to solving this complex crisis. Your expertise and experience are critical.

\section{Compliance with Ethical Standards}

Conflict of Interest: Louis A. Shapiro, FASCHE, declares that he has no conflict of interest. 
Required Author Forms Disclosure forms provided by the author are available with the online version of this article.

Publisher's Note Springer Nature remains neutral with regard to jurisdictional claims in published maps and institutional affiliations.

\section{References}

1. Dasgupta N, Beletsky L, Ciccarone D. Opioid crisis: no easy fix to its social and economic determinants. Am J Public Health. 2018;108(2):182-186.
2. Levy N, Sturgess J, Mills P. "Pain as the fifth vital sign" and dependence on the "numerical pain scale" is being abandoned in the US: Why? Brit J Anaesth. 2018;120(3): 435-438.

3. Manchikanti L, Sanapati J, Benyamin RM, Atluri S, Kaye AD, Hirsch JA. Reframing the prevention strategies of the opioid crisis: focusing on prescription opioids, fentanyl, and heroin epidemic. Pain Physician. 2018;21(4):309-326.

4. Meisenberg BR, Grover J, Campbell C, Korpon D. Assessment of opioid prescribing practices before and after implementation of a health system intervention to reduce opioid overprescribing. JAMA Netw Open. 2018;1(5):e182908.

5. U.S. Department of Health and Human Services. What is the U.S. opioid epidemic? 2018. Available from https://www.hhs.gov/opioids/.

6. Volkow ND, McLellan TA, Cotto JH, Karithanom M, Weiss SRB. Characteristics of opioid prescriptions in 2009. JAMA. 2011;305:1299-1301. 